\title{
Genetic variability, characters association and path analysis for yield and fruit quality components in Brinjal
}

\author{
A.V.V. Koundinya ${ }^{1 *}$, A. Das, S. Layek, R. Chowdhury and M. K. Pandit \\ ${ }^{1}$ Division of Crop Improvement, Central Tuber Crops Research Institute, Trivandrum, (Kerela), INDIA \\ Department of Vegetable Crops, Bidhan Chandra Krishi Viswavidyalaya, Mohanpur, (West Bengal), INDIA \\ *Corresponding author. E-mail: koundi.hortico@gmail.com \\ Received: November 18, 2016; Revised received: March 19. 2017; Accepted: July 2, 2017
}

\begin{abstract}
The experiment was done at AB District Seed Farm, BCKV, Kalyani Simanta, West-Bengal, India during autumn-winter 2013-14 and 2014-15. The characters that exhibited higher Phenotypic and Genotypic Co-efficient of variation values were number of fruits per plant $(76.86,75.63 \%)$, fruit weight $(43.88,41.34 \%)$, harvest index $(23.57$, $22.29 \%$ ), fruit yield per plant $(53.61,51.17 \%)$, anthocyanin in peel, total phenols and DPPH (2,2-diphenyl-I-picryl hydrazyl) free radical scavenging (FRS) capacity indicating that a greater amount of genetic variability was present for these characters which provide greater scope for selection. High heritability coupled with high genetic advance as percent of mean was observed for the characters like plant height, days to $1^{\text {st }}$ flowering, days to $50 \%$ flowering, number of fruits per plant, fruit weight, harvest index, fruit yield per plant, total sugar, anthocyanin in peel, total phenols and DPPH FRS capacity depicting that these traits were under the strong influence of additive gene action and hence simple selection based on phenotypic performance of these traits would be more effective. Fruit yield per plant showed highly positive significant correlation with number of primary branches per plant, number of fruits per plant, harvest index, vitamin-A and total phenols and significant negative correlation with days to 1st flowering, TSS, total sugars and total protein. Number of fruits per plant imparted the highest positive direct effect on yield followed by harvest index, fruit weight, days to $50 \%$ flowering and anthocyanin in peel. Number of fruits per plant and days to flowering were emerged as the main casual factors for positive or negative association of several characters with fruit yield per plant. Therefore, selection for fruit yield per plant based on these characters would be reliable.
\end{abstract}

Keywords: Brinjal, Correlation, Heritability, Path analysis, Variation

\section{INTRODUCTION}

Among all the vegetables, Brinjal or Aubergine or Eggplant [Solanum melongena L.] is an important vegetable crop growing in all states of India. India is the second largest producer of brinjal after China with an area and production of $0.71 \mathrm{mha}$ and $13.5 \mathrm{mt}$, respectively (NHB, 2015). In India, West-Bengal occupies first place with an area and production of $0.16 \mathrm{mha}$ and $0.29 \mathrm{mt}$ respectively (NHB, 2015). Brinjal is rich source of Anthocyanins, Vitamin-C and phenolic compounds, which are powerful antioxidants (Vinson et al., 1998). Nowadays, the demand for phytonutraceutically rich quality brinjal fruits without pest and disease infestation is increasing among the consumers. Most of the present day high yielding varieties and hybrids are very low in their nutrient content and quality aspects. A negative association between yield and quality characters has been observed by several workers in several crops like Thangamani and Jansirani (2012) and Karak et al. (2012) in brinjal. A breeder cannot sacrifice yield for any other reason, hence there is a need for combining quality and high yielding characters in upcoming varieties. As India is the primary centre of its diversity, she is rich in several indigenous varieties growing in different states of country. Local cultivars are popular in West-Bengal and their yield is less when compared to the hybrids. Moreover, the breeder's intention to breed quality rich, pest and disease resistant high yielding varieties has also been increasing. Therefore, evaluation of these genotypes for such characters may provide better outcome.

Being an often cross-pollinated crop, brinjal exhibits a good amount of variability for various characters. Co-efficient of variation is useful in the assessment of genetic variability for the particular characters. Heritability is an index of transmission of characters from parents to their offspring (Falconer, 1989). Heritability denotes the proportion of phenotypic variation repeatable and is due to genes and thus helps the breeders to select the elite variety for a character (Koundinya et al. 2013). High heritability alone is not enough to make efficient selection, unless information is accompanied by substantial amount of geneticadvance (Johnson et al., 1955). Genetic advance denotes the improvement in the mean values of selected families 
over the base population (Singh, 1983) and thus helps the breeder to select the progenies in the earlier generation itself.

Yield is a complex character and selection for yield is made based upon its component characters. Hence, there is a need for studying the association of various component characters with yield to formulate effective selection criteria. Association among various yield components facilitates the simultaneous selection for two associated traits. Correlation coefficient analysis assess the mutual relationship between two plant characters and establishes the yield components upon which selection is to be done for improvement in yield (Koundinya and Dhankhar, 2013). Path co-efficient analysis reveals the direct and indirect effect of various components characters on yield (Singh et al., 2011; Thangamani and Jansirani, 2012). It also says whether the association of a trait with yield is due to its own direct effect or indirectly through another character. All the above-mentioned parameters are the pre-requisites to formulate a sound and successful breeding programme. Therefore, a research work was undertaken to estimate the amount of the variability present in the local cultivars and other genotypes of brinjal and to study the association of yield components and fruit quality parameters.

\section{MATERIALS AND METHODS}

The present study was carried out at the AB District Seed Farm, BCKV, Kalyani Simanta, West-Bengal, India during autumn-winter2013-14 and 2014-15. The experiment was laid out in a Randomized Block Design (RBD) with two replications and with fourty genotypes of brinjal which include local cultivars; genotypes and varieties collected from all over the country. In each replication each genotype was grown in a plot of $3 \times 2.25 \mathrm{~m}$ size accommodating 12 plants with the row-to-row spacing of $75 \mathrm{~cm}$ and plant-to-plant spacing of $75 \mathrm{~cm}$. Observations were recorded on various morphological (plant height $(\mathrm{cm})$, number of primary branches per plant), yield (days to first flowering, days to $50 \%$ flowering, number of fruits per plant, fruit weight $(\mathrm{g})$, harvest index, fruit yield per plant $(\mathrm{g})$ and fruit biochemical characters. Total Soluble Solids (TSS) was determined by digital refractometer and expressed in Brix. Total sugars (\%) were estimated through phenol-sulphuric acid method as per Dubois et al. (1956). Total protein (\%) was measured by Kjeldhal method. Anthocyanin content in peel $(\mathrm{mg} / \mathrm{g})$ and vitamin-A(IU/g) contents were determined as per Srivastava and Kumar (2002). For estimation of vitamin- $\mathrm{C}(\mathrm{mg} / \mathrm{g})$, the procedure proposed by Sadasivam and Balasubraminan (1987) was followed. Moisture content was estimated by weight loss (\%) method after drying the fresh fruit. Total phenolic contents (GAE $\mathrm{mg} / \mathrm{g}$ ) of dry fruit were determined using Folin-ciocalteu reagent and ex-pressed as gallic acid equivalents (GAE) (Singleton and Ross, 1965). The antioxidant capacity of the dry fruit was estimated as DPPH (2,2-diphenyl-1picryl hydrazyl) free radical scavenging capacity and expressed in Trolox equivalents (TE mg/g) (Leong and Shui, 2001).

Both phenotypic and genotypic co-efficient of variability for all characters were estimated using the formula of Burton (1952). The broad sense heritability $\left(\mathrm{h}^{2}\right.$ bs $)$ was estimated for all the characters as the ratio of genotypic variance to the total or phenotypic variance as suggested by Hanson et al. (1956). The expected genetic gain or advance for each character was estimated by using the following method suggested by Johnson et al. (1955). Both genotypic and phenotypic coefficients of correlation between two characters were determined by using the variance and covariance components as suggested by Al-Jibouriet al. (1958). Path coefficient analysis was carried out using genotypic correlation values of yield components on yield as suggested by Wright (1921) and illustrated by Dewey and $\mathrm{Lu}(1959)$.

\section{RESULTS AND DISCUSSION}

Various genetic parameters like phenotypic and genotypic co- efficient of variability (PCV, GCV), heritability $\left(\mathrm{h}^{2} \mathrm{bs}\right)$, genetic advance (GA) and genetic advance as per cent of mean (GAM) for the 17 quantitative characters were measured and presented in Table 1 . Significant differences were observed among all the genotypes for all the characters except for moisture content of fruit through analysis of variance study. This indicated the presence of sufficient variability in the genetic material under study and it was sufficient enough to carry out further analysis.

Closer PCV and GCV values were observed for majority of the characters in the present study, and possibly they were less influenced by the environment indicating the reliability of selection based on these traits. The characters that exhibited higher PCV and GCV values were number of fruits per plant $(76.86 \%, 75.63 \%)$, fruit weight (43.88\%, 41.34\%), harvest index $(23.57 \%$, $22.29 \%$ ), fruit yield per plant $(53.61 \%, 51.17 \%)$, anthocyanin in peel $(98.87 \%, 98.31 \%)$, total phenol $(23.86 \%, 22.66 \%)$ and DPPH (2,2-diphenyl-1-picryl hydrazyl) free radical scavenging (FRS) capacity $(38.45 \%, 37.60 \%)$ indicating that a greater amount of genetic variability was present for these characters which provide greater scope for selection. Singh and Kumar (2005), Karak et al. (2012), Kumar and Arumugam (2013), Yadav et al. (2014) and Solaimana et al. (2015) found similar type of results previously in brinjal.

More than half of the characters exhibited high broad sense heritability values viz., plant height $(80.76 \%)$, days to $1^{\text {st }}$ flowering $(97.79 \%)$, days to $50 \%$ flowering $(90.15 \%)$, number of flowers per plant $(96.8 \%)$, fruit 
A.V.V. Koundinya et al. / J. Appl. \& Nat. Sci. 9 (3): 1343 -1349 (2017)

Table 1. Estimation of various genetic parameters for various characters in brinjal.

\begin{tabular}{clccccc}
\hline S. No. & \multicolumn{1}{c}{ Character name } & PCV (\%) & GCV (\%) & $\mathbf{h}^{\mathbf{2}} \% \mathbf{( b s )}$ & GA & GAM \\
\hline 1 & Plant height (cm) & 17.77 & 15.97 & 80.76 & 21.39 & 29.57 \\
2 & Number of primary branches/plant & 13.58 & 08.68 & 40.90 & 00.65 & 11.44 \\
3 & ${\text { Days to } 1^{\text {st }} \text { flowering }}_{4}$ & 13.02 & 12.88 & 97.79 & 19.86 & 26.24 \\
4 & Days to 50\% flowering & 11.04 & 10.48 & 90.15 & 17.02 & 020.5 \\
5 & Number of fruits/Plant & 76.86 & 75.63 & 96.82 & 20.06 & 153.3 \\
6 & Fruit weight (g) & 43.88 & 41.34 & 88.78 & 98.08 & 80.25 \\
7 & Harvest index & 23.57 & 22.29 & 89.45 & 00.27 & 43.44 \\
8 & Fruit yield/plant (g) & 53.61 & 51.17 & 91.10 & 1254.2 & 100.61 \\
9 & TSS ( ${ }^{\circ}$ Brix) & 11.16 & 07.74 & 48.02 & 00.60 & 11.04 \\
10 & Moisture (\%) & 7.77 & 4.22 & 29.50 & 4.24 & 4.72 \\
11 & Total protein (\%) & 08.00 & 03.15 & 15.48 & 00.04 & 02.55 \\
12 & Total sugars (\%) & 15.64 & 13.71 & 76.75 & 00.36 & 24.74 \\
13 & Vitamin- C (mg/g) & 08.17 & 3.54 & 18.80 & 00.01 & 03.16 \\
14 & Vitamin- A (IU/g) & 12.63 & 10.26 & 65.95 & 00.04 & 17.16 \\
15 & Anthocyanin in peel (mg/g) & 98.87 & 94.31 & 87.87 & 26.67 & 189.84 \\
16 & Total phenols ( GAE mg/g) & 23.86 & 22.66 & 90.20 & 00.87 & 44.33 \\
17 & DPPH FRS Capacity (TE mg/g) & 38.45 & 37.60 & 95.63 & 58.82 & 75.74 \\
\hline
\end{tabular}

weight $(88.78 \%)$, harvest index $(89.45 \%)$, fruit yield per plant $(91.10 \%)$, total sugars $(76.75 \%)$, vitamin- A $(65.95 \%)$, anthocyanin in peel $(87.87 \%)$, total phenols $(90.20 \%)$ and DPPH FRS capacity $(95.63 \%)$ suggesting that the selection based on phenotypic performance of these traits would be more effective. The characters like number of branches per plant $(40.9 \%)$ and TSS $(48.02 \%)$ displayed medium level of heritability.

High genetic advance as percentage of mean (GAM) was observed for the characters plant height (29.57\%), days to $1^{\text {st }}$ flowering $(26.24 \%)$, days to $50 \%$ flowering $(20.50 \%)$, number of fruits per plant $(153.30 \%)$, fruit weight $(80.25 \%)$, harvest index (43.44\%), anthocyanin in peel $(189.84 \%)$, DPPH FRS capacity $(75.74 \%)$ and fruit yield per plant $(100.61 \%)$. This revealed that greater improvement in the population mean could be observed if selection was carried out for next generation for these characters. The characters like number of branches per plant (11.44\%), TSS (11.04\%) and vitamin-A (17.16\%) showed moderate level of GAM.

High heritability coupled with high genetic advance as per cent of mean was observed for the characters like plant height, days to $1^{\text {st }}$ flowering, days to $50 \%$ flowering, number of fruits per plant, fruit weight, harvest index, fruit yield per plant, total sugars, anthocyanin in peel, total phenols and DPPH FRS capacity. It indicated that these traits were under the strong influence of additive gene action and hence simple selection based on phenotypic performance of these traits would be more effective. Moderate heritability and moderate GAM values were observed for the characters' number of branches and TSS recognizing considerable influence of environment on the expression of these traits. High heritability with moderate genetic advance was found for the character
vitamin-A. Characters with high heritability with low genetic advance were controlled by non-additive gene action i.e. either dominant or epistatic gene action indicating that these characters in brinjal could be exploited through development of hybrids.

High heritability coupled with high genetic advance for anthocyanin content, total phenols and total sugars was observed previously by Doshi et al. (1999). Singh and Kumar, (2005), Sherly and Shanthi, (2009), Chattopadhyay et al. (2011), Kumar et al., (2012), Kumar and Arumugam (2013) and Solaimana et al., (2015) also gained same kind of outcome for various characters in brinjal.

The genotypic and phenotypic correlation coefficients were worked out for 17 morphological, yield and fruit quality characters of the 40 brinjal germplasm based on data obtained from AW season and the details of which have been presented in Table-2. It was evident from the table that the values of genotypic correlation coefficient were greater than the values of phenotypic correlation co efficient for most of the characters, which indicate a strong inherent association between various traits that were quite influenced by the environment.

Fruit yield per plant showed highly positive significant correlation with number of primary branches per plant (0.240), number of fruits per plant $(0.767)$, harvest index (0.862) and vitamin-A (0.240). It had also significant negative correlation with days to $1 \mathrm{st}$ flowering (-0.264), TSS (-0.447), total sugars $(-0.289)$ and total protein $(-0.220)$.

Selection for fruit yield per plant should be based on high mean values of number of primary branches per plant, number of fruits per plant, harvest index and low mean values of days to flowering. Direct selection 
A.V.V. Koundinya et al. / J. Appl. \& Nat. Sci. 9 (3): 1343 -1349 (2017)

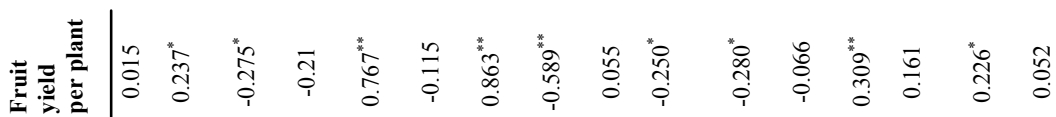

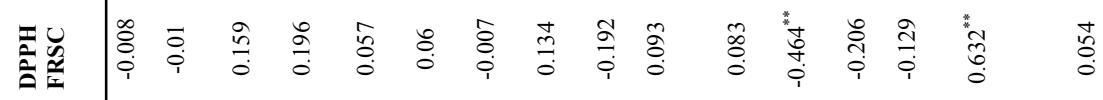

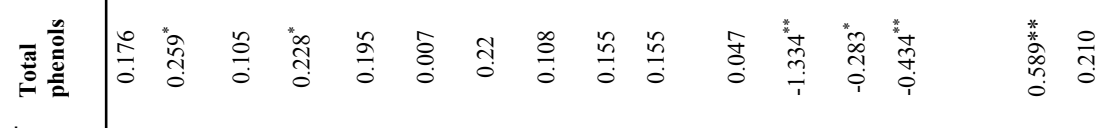

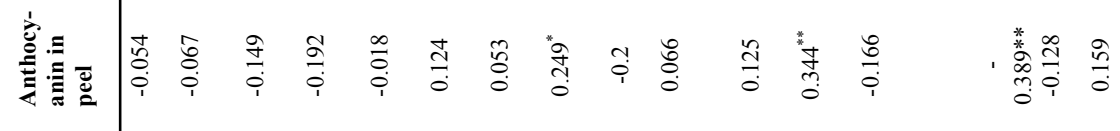

彦考

产崖

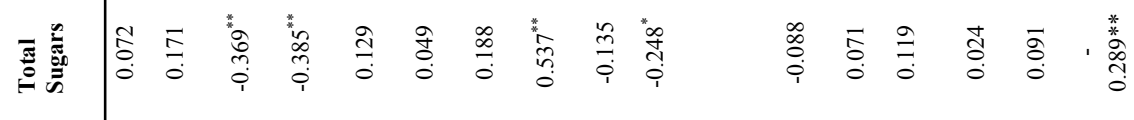

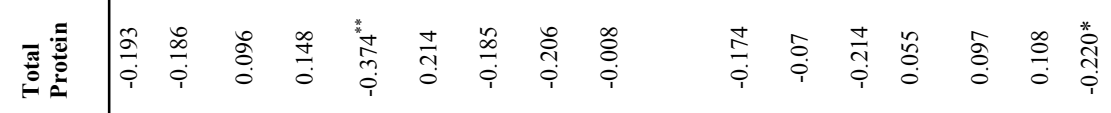

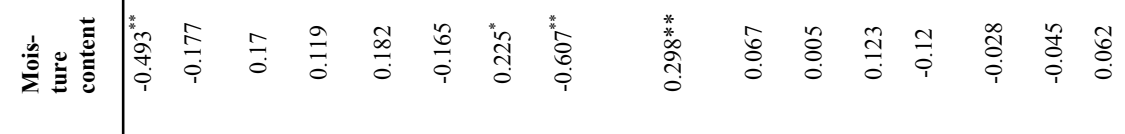

Q

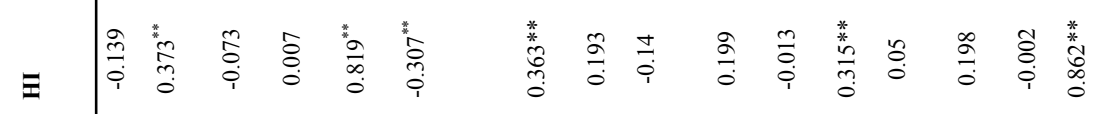

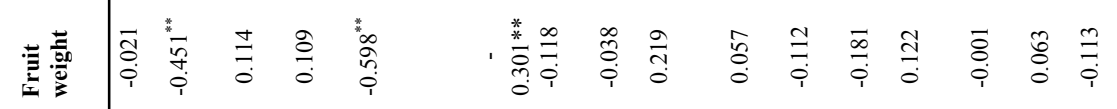



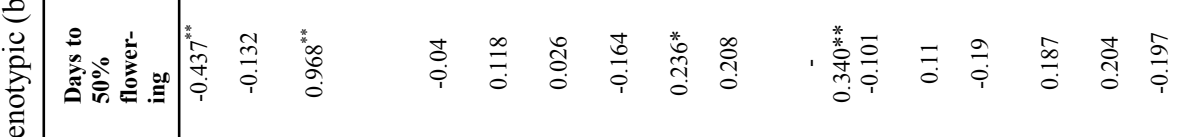

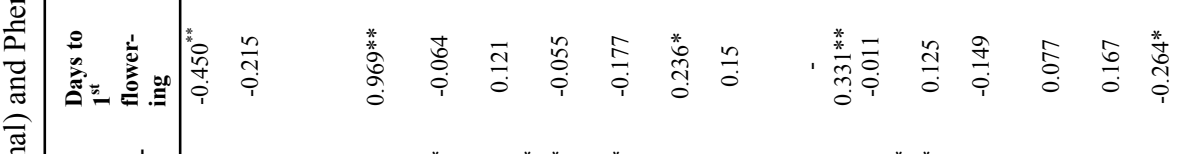

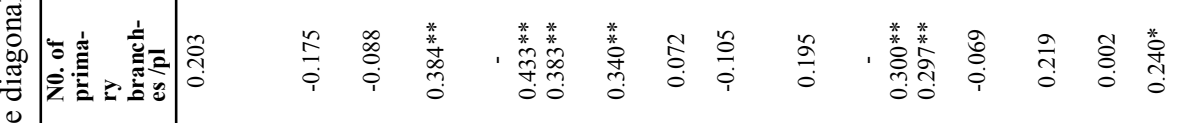

产言

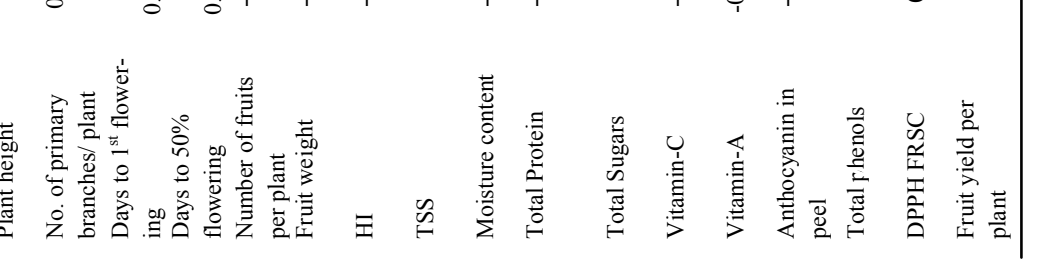


A.V.V. Koundinya et al. / J. Appl. \& Nat. Sci. 9 (3): 1343 -1349 (2017)

新

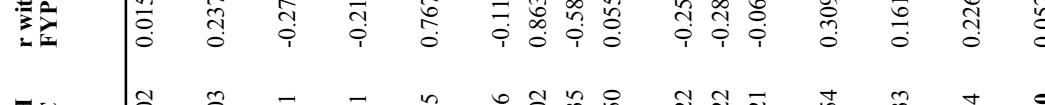

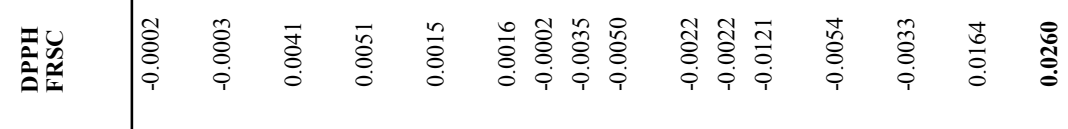



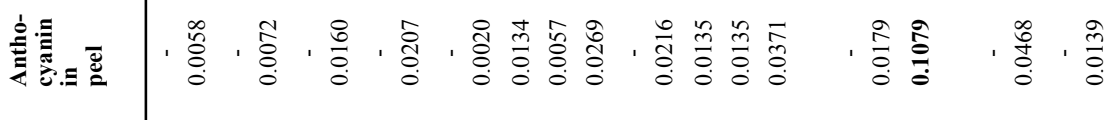

产紊

旁产

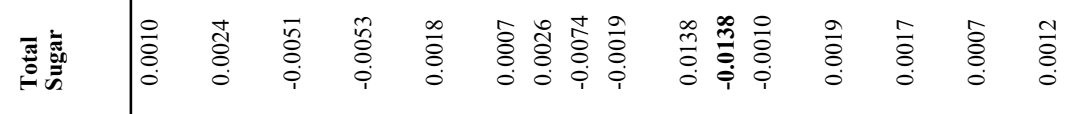

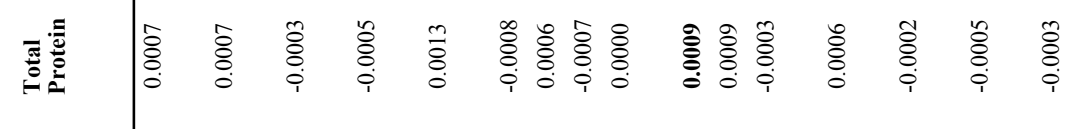

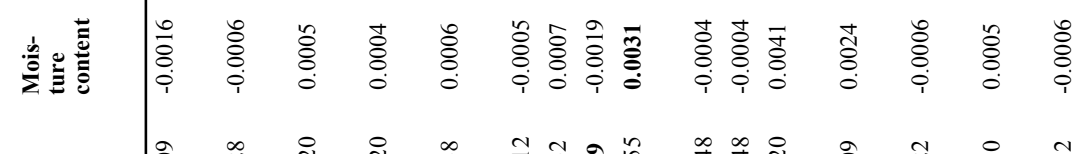

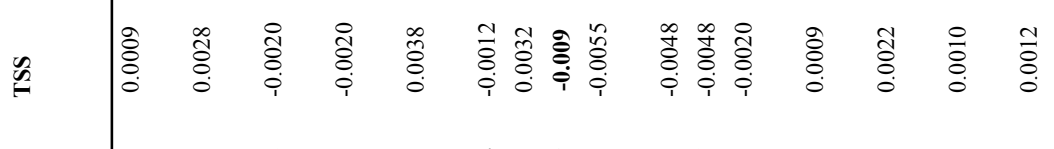

I |

言言

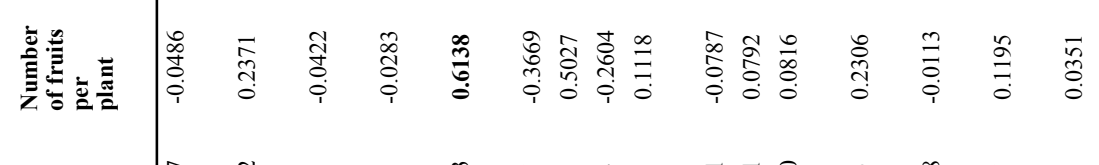

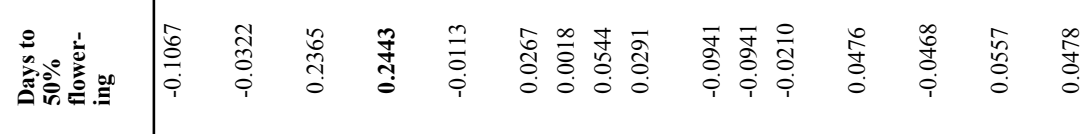

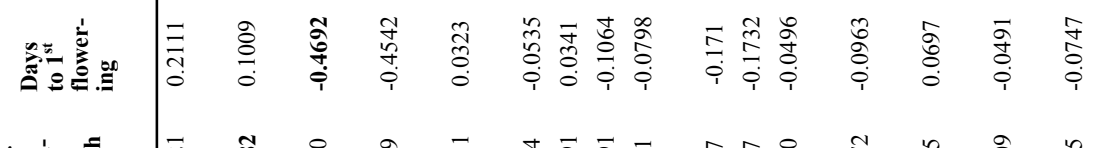

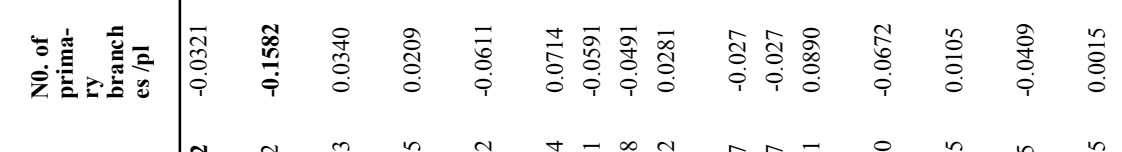

言衰

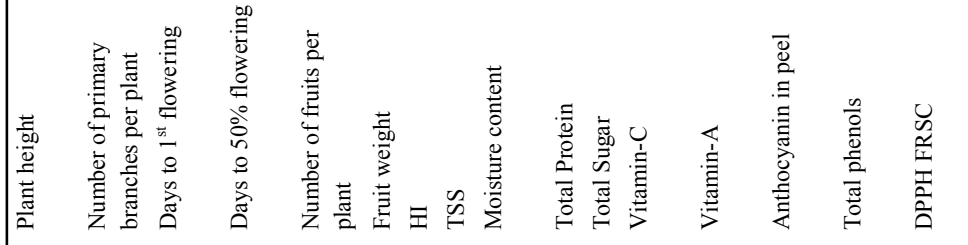


based on these traits would result in simultaneous improvement of aforesaid traits and yield per se in brinjal. Similar to many cases, here also a negative association between fruit yield per plant and fruit quality parameters viz., TSS, total sugars and total protein was observed which suggested that improvement in fruit yield reduces the fruit quality. Another undesirable correlation found in present study was positive association between total phenols and fruit yield. Again the selection for lower phenol content would demand sacrifice in yield.

Inter correlations between various components of yield were essential to study as improvement in one character would simultaneously improve the performance of other character if the both were positively correlated. Some important inter correlations were positive correlation of primary branches per plant with number of fruits per plant (0.384) and harvest index (0.383); days to first flowering with days to $50 \%$ flowering (0.969); number of fruits per plant with harvest index (0.818) and negative correlation of plant height with days to first $(-0.418)$ and $50 \%$ flowering (-0.399); primary branches per plant with fruit weight $(-0.433)$; fruit weight with number of fruits per plant $(-0.595)$ and harvest index $(-0.301)$.

It was quite evident that fruit weight gets reduced with increasing the number of fruits per plant. Physiologically with increasing the numbers of sinks, the photosynthates are distributed among all and lesser will be the size of sinks and vice versa. Earlier flowering or early conversion to reproductive stage reduces the plant vegetative growth which resulted in the negative association between days to flowering and plant height. Number of branches per plant also had negative correlation co-efficient values though they are of low magnitude.

These correlations among the yield components were in agreement with that of Chattopadhyay et al. (2011), Singh et al. (2011), Karak et al. (2012) Kranthirekha and Celine (2013), Prabhu and Natarajan (2008), Dharwad et al. (2009), Thangamani and Jansirani (2012) and Solaimana et al. (2015) in brinjal.

It was quite obvious that positive correlation were found between TSS and total sugars; total phenols and DPPH FRS capacity; and negative correlation between moisture content and TSS. Other correlations were positive association of TSS and anthocyanin in peel; vitamin-A with vitamin- $\mathrm{C}$; anthocyanin in peel with vitamin-C; negative association between total phenols and anthocyanin in peel. Significant positive correlation between total phenol content DDPH FRSC was previously observed by Jung et al. (2011) in brinjal.

The correlation coefficient of each independent quantitative character was partitioned into direct and indirect effect towards yield. Genotypic path coefficient values of different characters of 40 brinjal genotypes were presented in Table-3. As the residual effect was very low $(0.07)$, it is therefore, indicated that the number of characters chosen for the study were very much appropriate for determination of fruit yield in Brinjal. More than half of the characters viz., plant height, days to $50 \%$ flowering, number of fruits per plant, fruit weight, harvest index, moisture content, total protein, vitamin-A, anthocyanin in peel, total phenols and DPPH FRSC showed positive direct effects towards fruit yield. Among these, number of fruits per plant (0.6138) imparted the highest positive direct effect on yield followed by harvest index (0.4566), fruit weight $(0.3382)$, days to $50 \%$ flowering $(0.2443)$ and anthocyanin in peel (0.1079).

Characters like number of fruits per plant, harvest index, vitamin-A and total phenols showed positive direct as well as significant positive correlation with fruit yield per plant. Selection based on these characters would be highly effective. Though days to $50 \%$ flowering and fruit weight imparted moderate to high positive direct effect on fruit yield per plant, negative correlation coefficient with fruit yield per plant indicated that the negative indirect effects are the cause of manifestation of the correlation. Therefore, a restricted selection model may be followed to nullify the undesirable indirect effects in order to make the use of high positive direct effect of fruit weight in brinjal improvement programme.

Number of primary branches per plant had significantly positive correlation with fruit yield per plant but had negative direct effect $(-0.1582)$ on fruit yield per plant indicating the high indirect effect through number of fruits per plant $(0.2371)$ was the main cause for the revelation of such a correlation coefficient. Similarly total protein content was having low direct effect $(0.0009)$ but its negative correlation with fruit yield per plant was due to high negative indirect effect through days to first flowering $(-0.0941)$. The negative correlation of TSS and total sugars with fruit yield per plant was also because of own negative effect besides high negative indirect effect through number of fruits per plant $(-0.2604)$ and days to first flowering $(-0.1732)$ respectively. Number of fruits per plant again was indirectly responsible for positive correlations of vitamin-A(0.2306) and total phenols $(0.1195)$ with fruit yield per plant as the direct effects of vitamin-A(0.0695) and total phenols (0.0021) was low. In this circumstance, causal factors with high positive indirect effect should be considered during selection for yield improvement in brinjal.

\section{Conclusion}

Number of fruits per plant, fruit weight, harvest index, fruit yield per plant, anthocyanin in peel, total phenol and DPPH (2,2-diphenyl-1-picryl hydrazyl) free radical scavenging (FRS) capacity had high GCV and PCV suggesting the scope for greater selection for these 
traits. Besides, their high heritability and GAM values hint the improvement of these traits through the simple selection. Fruit yield per plant showed highly positive significant correlation with number of primary branches per plant, number of fruits per plant, harvest index. Number of fruits per plant and days to flowering were emerged as the main casual factors for positive or negative association of several characters with fruit yield. Moreover, the high direct effect of these traits suggested that selection for yield can be taken up based on these traits.

\section{ACKNOWLEDGEMENTS}

The first author is highly thankful to the Department of the Science and Technology, Government of India for financial assistance through INSPIRE fellowship.

\section{REFERENCES}

AL-Jibouri, H.A., Miller, P.A. and Robinson, H.F. (1958). Genotypic and environmental variances and co-variances in an upland cotton cross of interspecific origin. Agron. J., 50: 633-636

Burton, G.W. (1952). Quantitative inheritance in grasses. Proc. Int. Grassland Cong., 1: 277-283

Chattopadhyay, A., Dutta, S. and Hazra, P. (2011). Characterization of genetic resources and identification of selection indices of brinjal (Solanum Melongena L.) grown in eastern India.Veg. Crops Res. Bull., 74: 39-49

Dewey, D.R. and Lu, K.H. (1959). A correlation and path coefficient analysis of component of crested wheatgrass seed production. Agron. J., 52: 515-518.

Doshi, K.M., Bhalala, M.K. and Kathiria, K.B. (1999). Genetic variability for yield, fruit borer infestation, little leaf incidence and quality characters in brinjal. Gujarat Agri. Univ. Res. J., 24(2): 27-30

Dubois, M.,Gilles, K.A., Hamilton, J.K., Robers, P.A. and Smith, F. (1956). A colorimetric method for the determination of sugar. Analy. Chem., 28: 350-356.

Falconer, D.S. (1989). Introduction to quantitative Genetics, $3^{\text {rd }}$ ed. Longman, NewYork.

Hanson, C.H., Robinson, H.F. and Comstock, R.E. (1956). Biometrical studies of yield in segregating population of Korean lespedse. Agron. J., 48: 267-282.

Johnson, H.W., Robinson, H.F. and Comstock, R.E. (1955). Estimates of genetic and environmental variability in soybean. Agron. J., 47: 314-318.

Jung, E.J., Bae, M.S., Jo, E.K., Jo, Y.H. and Lee, S.C. (2011). Antioxidant activity of different parts of eggplant. J. Med. Pl. Res., 5(18): 4610-4615.

Karak, C., Ray, U., Akhtar, S., Naik, A. and Hazra, P. (2012). Genetic variation and character association in fruit yield components and quality characters in brinjal [Solanum melongena L.]. J. Crop Weed, 8(1): 86-89

Koundinya, A.V.V. and Dhankhar, S.K. (2013). Correlation and path analysis of seed yield components in Okra Abelmoschus esculentus (L.) Moench. Ann. Horti., 6(1): 145-148

Koundinya, A.V.V., Dhankhar, S.K. and Yadav, A.C. (2013). Genetic variability and divergence in okra (Abelmoschus esculentus). Indian J. Agri. Sci., 83(6): 685-688

Kranthirekha, G. and Celine, V.A. (2013). Correlation and path analysis studies in round fruited brinjal. Veg. Sci.,40(1): 87-89

Kumar, S.R. and Arumugam, T.(2013). Variability, heritability and genetic advance for fruit yield, quality and pest and disease incidence in eggplant.Veg. Sci., 40(1): 111-113

Kumar, S.R., Arumugam, T. and Premalakshmi, V. (2012). Evaluation and variability studies in local types of brinjal for yield and quality (Solanum melongena L.). Elec. J. Pl. Breed., 3(4): 977-982

Leong, L.P. and Shui, G. (2001). An investigation of antioxidant capacity of fruits in Singapore market. Food Chem., 76: $69-75$

NHB (2015). Indian Horticulture Database-2015, National Horticulture Board, Ministry of Agriculture, Government of India.

Prabhu, M. and Natarajan, S. (2008). Correlation and path analysis in brinjal. Madras Agri. J.95(1-6): 184-187

Sadasivam, S. and Balasubraminan, T. (1987). In: Practical Manual in Biochemistry. Tamil Nadu Agriculture University Coimbatore.

Sherly, J. and Shanthi, A. (2009). Variability, heritability and genetic advance in brinjal (Solanum melongena L.). Res. on Crops, 10(1): 105-108.

Singh, A.K., Tripathi,M.K., Rai,V.K. and Mishra,R.(2011). Character association and path coefficient analysis in brinjal (Solanum melongena L.). Envi. Ecol., 29(3): 1201-1203.

Singh, B.D. (1983). Plant breeding principles and methods, Kalyani Publishers, New Delhi, 494-516

Singh, O. and Kumar, J. (2005). Variability, heritability and genetic advance in brinjal. Indian J. Horti.62(3): 265267.

Singleton, V.L. and Ross, J.A. (1965). Colorimetry of total phenolic with phosphomolybdate-phosphotungstic acid reagent. American J. Eno. Viticul., 16: 44-158

Solaimana, A.H.M., Nishizawa, T., Khatun, M. and Ahmad, S.(2015). Physio morphological characterization genetic variability and correlation studies in brinjal genotypes of Bangladesh. Comp. Math. Biol., 4(1): 1-36

Srivastava, R.P. and Kumar S. (2002). Fruit and Vegetable Preservation: principles and Practices, $3^{\text {rd }}$ ed. IBDC Publishers, Lucknow, U.P. India.

Thangamani, C. and Jansirani, P. (2012). Correlation and path coefficient analysis studies on yield attributing characters in brinjal. Elec. J. Pl. Breed, 3(3): 939-944

Vinson, J.A., Hao, Y., Su, X. and Zubik, L. (1998). Phenol antioxidant quantity and quality in foods: vegetables. J.Agri. Food Chem., 46: 3630-3634. 